\title{
Evolution of the Health System
}

Inefficiency, Violence, and Digital Healthcare

\section{Carine Milcent}

Translator. David Buchanan

\section{(2) OpenEdition}

\section{Journals}

\section{Electronic version}

URL: http://journals.openedition.org/chinaperspectives/7112

DOI: 10.4000/chinaperspectives.7112

ISSN: 1996-4617

\section{Publisher}

Centre d'étude français sur la Chine contemporaine

\section{Printed version}

Date of publication: 1 December 2016

Number of pages: $39-50$

ISSN: 2070-3449

\section{Electronic reference}

Carine Milcent, "Evolution of the Health System », China Perspectives [Online], 2016/4 | 2016, Online since 01 December 2017, connection on 10 December 2020. URL : http://journals.openedition.org/ chinaperspectives/7112; DOI : https://doi.org/10.4000/chinaperspectives.7112 


\title{
Evolution of the Health System
}

\author{
Inefficiency, Violence, and Digital Healthcare
}

\author{
CARINE MILCENT
}

\begin{abstract}
China's public health system has gone through a number of development stages. This paper aims at showing how, from its inception as a hierarchical system, the healthcare system then lost its structure, to finally give birth to a focalised system where the first point of entry in the treatment process has become the hospital, in particular the healthcare establishments that offer the most reliable standards of care. These days, the widely-acknowledged inefficiencies of the healthcare system have led to a climate of violence between medical staff and their patients, caused by the overwhelming demand that hospitals must bear, the ambiguous status of public establishments, financial benefits and other perks for medical staff, as well as the medical staff's civil servant status, and the implications thereof. Policies to foster the development of primary health centres are struggling to gain traction, while digital healthcare offers promising solutions and is developing fast.
\end{abstract}

KEYWORDS: healthcare system, hospital, inefficiency, violence, digital healthcare.

\section{Introduction}

T oday, China's public hospitals manage $90 \%$ of consultations for what English-speakers would call ambulatory care or outpatient care, and $90 \%$ of hospital inpatient admissions. ${ }^{(1)}$ As such, public hospitals deal with demands for treatment by consultation just as they must deal with treatment for inpatients.

China is in the midst of a paradox. There has been a spectacular upward surge in health indicators, matching the similar increase in economic indicators. It is also a colossal market, with healthcare expenditures reaching $\$ 511.3$ billion in 2013. (2) That is equivalent to 5.6\% of GDP. (3) On the other hand, the health system has officially been described as inefficient, and there is a toxic atmosphere between medical staff and patients.

Before we examine the healthcare system in all its various permutations, we will first offer a brief overview of the current state of China's health and healthcare. In 2015, mainland China had a natural population growth of 5.21 per thousand, with a crude birth rate of $12.37 \%$ and a crude death rate of $7.16 \%$. Urban residents now account for $54.8 \%$ of the total population (or 1.4 billion people). The population is $51.2 \%$ male and $48.8 \%$ female. (4) Life expectancy has improved considerably over the years: while in 1990 it was 67 years for men and 70 for women, by 2010 it had risen to 72.5 for men and 76.8 for women. Likewise, the mortality rate for children under five and the maternal mortality rate have seen distinct improvements. However, it is also apparent that medication (especially antibiotics) is currently being over-consumed. It is acknowledged that $70 \%$ of prescription medicines contain antibiotics. ${ }^{(5)}$ One consequence of this inappropriate medication use is an increase in morbidity and mortality. Lianping Yang et alii ${ }^{(6)}$ estimate that each year, 2.5 million patients are admitted to hospital suffering from unwelcome medicinal side-effects. ${ }^{(7)}$

On the economic front, gross domestic product (GDP) is not far behind that of the United States. ${ }^{\left({ }^{8}\right)}$ While the growth rate appears to be slowing down, ${ }^{(9)}$ it is nonetheless expected to reach $6.9 \%$ for the year 2016. ${ }^{(10)}$ Overall, the general level of wealth among the population is on the rise. In
1990 the per capita GDP was 1,644 RMB, whereas by 2012 it had reached 38,420 RMB.

As a result, the Chinese healthcare system has been forced to adapt, not only to demographic changes but also to a demand for new treatments: from dealing with a low-income population with a high birth rate and high death rate, primarily requiring basic care, it has moved to looking after a comparatively older population with a low birth rate and higher income, demanding ever-more-effective healthcare treatment. Since the economic reforms, the expected level of treatment quality has risen considerably, which de facto reduces the number of establishments able to meet these expectations to only the very best urban hospitals, thus creating high demand and low supply for said treatment, while less reliable healthcare establishments have found themselves in a situation where there is too much supply, but insufficient demand.

1. Jeffrey Moe, Shu Chen, and Andrea Taylor, "Initial Findings in a Landscaping Study of Healthcare Delivery Innovation in China," IPIHD (International Partnership for Innovative Healthcare Delivery) research Report 14-01, 2014; Xuezheng Qin, Lixing Li, and Chee-Ruey Hsieh, "Too Few Doctors or Too Low Wages? Labor Supply of Healthcare Professionals in China," China Economic Review, Vol. 24, No. 1, 2013.

2. "Industry Report, Healthcare: China," The Economist Intelligence Unit, August 2014.

3. The proportion of GDP spent on healthcare was $4 \%$ in 1990. It is $17 \%$ In the United States.

4. National Bureau of Statistics of China, "Statistical Communiqué of the People's Republic of China on the 2014 National Economic and Social Development," 26 February 2015, www.stats.gov.cn/ english/PressRelease/201502/t20150228_687439.html (accessed on 26 October 2016). The figures presented here do not include Hong Kong, Macao, or Taiwan.

5. Lucy Reynolds and Martin McKee, "Factors Influencing Antibiotic Prescribing in China: An Exploratory Analysis," Health Policy, Vol. 90, No. 1, 2009, pp. 32-36.

6. Lianping Yang, Chaojie Liu, J. Adamm Ferrier, Wei Zhou, and Xinping Zhang, "The Impact of the National Medicines Policy on Prescribing Behaviours in Primary Care Facilities in Hubei Province of China," Health Policy Plan, Vol. 28, No. 7, 2013, pp. 750-760.

7. It is thought that the excessive use of antibiotics and particularly ototoxic medicines accounts for $60 \%$ of hearing loss among children.

8. According to figures from the International Monetary Fund (IMF), in 2014 China's GDP was slightly higher than that of the United States.

9. The rate of growth was $10.6 \%$ in 2010 .

10. "China Economic Outlook," FocusEconomics, 18 October 2016. Source: People's Bank of China, 2017. 
This demand for healthcare provided by "trained and qualified" medical staff has led to a decrease in the supply available to meet the demand, and therefore to ever-longer waiting times and ever-shorter consultations. Treatment prices have shot up, which can be explained in part by the lack of qualified staff on offer, but also by the state's withdrawal of funding from public hospitals. Moreover, doctors with a financial stake in the profitability of their establishment tend to over-prescribe and overdiagnose, and the cost of medication has shot up, all against a backdrop of corruption.

The doctor-patient relationship has therefore been transformed into a dynamic of conflict in the face of exorbitant treatment costs, extremely long waiting times, ever-shorter consultation appointments, and the increasingly widespread practice of bribery. Paying money under the table helps to reduce the waiting time and ensure better medical care for the patient.

In recent years, a number of forms of violence have been witnessed in Chinese hospitals. It might be a comparatively non-aggressive form of blame, such as families displaying the dead body of a loved one outside a hospital; but it can also take a more active form, ranging from fights and damage to premises to extremely violent acts inflicted on medical personnel, sometimes even involving help from organised gangs. (11) When entered into the usual search engines, the keywords "hospital, violence" bring up hundreds of news articles relating stories of doctors who have been injured or killed by patients. ${ }^{12)}$

In July 2015, an article in China Daily reported a 600,000-strong online petition by doctors calling for an end to attacks on medical staff. ${ }^{(13)}$ This petition came in the wake of one patient's violent attack on a doctor during his shift at a Tier-3 hospital (Longmen xian renmin yiyuan 龙门县人民医院) in Guangdong Province. The local health and family planning commission responded by demanding that a police branch be set up inside the hospital, and regular patrols carried out, in order to facilitate swifter intervention in the event of violence. Surveillance cameras and alarms were also installed. ${ }^{(14)}$

The healthcare system has been through several phases of development. The economic reforms of the 1980s introduced market mechanisms to varying degrees, leading to extreme disparities in access to healthcare, not only between rural and urban areas, but also within the areas themselves. After that, it became necessary to ensure that basic healthcare was accessible to all. There were two co-existing philosophies: universal access to basic treatment thanks to a tightly-regulated market, while for other forms of treatment, competition would be encouraged to develop within the private sector. The new series of reforms (15) were announced in March 2009 by the State Council of the People's Republic of China and the Central Committee of the Chinese Communist Party. They were followed by the 12th Five-Year Plan (2012-2016), and now by the 13th Five-Year Plan (20162020), which sets out new directions for the future.

Henceforth, the health sector is booming. On one hand, the number of medical and health establishments is constantly growing. This growth in supply is visible in urban and rural areas alike, and in both the public and private sectors. Nonetheless, there are major disparities to this growth, which this paper will proceed to explore. ${ }^{(16)}$ On the other hand, the sector is employing an ever-growing number of people. In 2015, it accounted for 7.39 million workers. ${ }^{(17)}$ Behind these increases lies a real political desire to expand the network of hospitals and healthcare. The demographic changes within Chinese society also entail an increased number of social welfare establishments. ${ }^{(18)}$
However, one obstacle to the creation of this system is the lack of mobility among medical personnel. Due to their status (equivalent to that of a civil servant, with a certain number of additional privileges), medical personnel display a strong preference for working within a public organisation. For reasons that will be explained later, medical personnel that meet the new standards of demand for "trained and qualified" staff are only found in the largest, highest-performing public establishments. ${ }^{(19)}$ The result of this is that, while the supply is diversifying, the demand remains centred on the highest-quality public establishments.

The Internet would appear to provide a solution to this concentration of demand. In a later section, I will show how the Internet is being considered as a solution to help resolve the endless waiting-room queues at high-quality public health establishments. I will explain the Internet's role in easing pressure thanks to its potential as a telemedicine tool, but also a tool for remote advice and consultation. ${ }^{(20)}$ The result is that public hospitals appear more accessible, thanks to the fact that patients no longer need to queue in the waiting room, and demand is more manageable. Similarly, if the demand for consultations that would usually be held at a public establishment can be partially met via the Internet, this could also lead to a reduction in demand for treatment. If the pressure of demand is eased somewhat, it is likely that waiting times will be reduced and consultations made longer, thereby improving dialogue between medical staff and patients. Furthermore, this also introduces a form of competition between physical consultations and virtual consultations, which may allow for the cost of physical consultations to be lowered. However, the solutions offered by the Internet are not without their drawbacks, raising issues such as data confidentiality, the identity of the staff responsible in the event of medical wrongdoing, and also the question of standardising and supervising the quality of service on offer.

11. Jiong Tu, "Yinao: Protest and Violence in China's Medical Sector," Berkeley Journal of Sociology, 11 December 2014, http://berkeleyjournal.org/2014/12/yinao-protest-and-violence-in-chinasmedical-sector (accessed on 26 October 2016).

12. A recent example: Xinhua, "Doctor Dies after Stabbing Attack in Guangzhou," China Daily Asia, 7 May 2016, www.chinadailyasia.com/nation/2016-05/07/content_15429118.html (accessed on 26 October 2016).

13. "600,000 Chinese Doctors Sign Petition against Hospital Violence," China Daily, 19 July 2015, www.chinadaily.com.cn/china/2015-07/19/content_21326495.htm (accessed on 26 October 2016).

14. During my multiple visits to Tier-3 hospitals in Beijing and Shanghai, I also observed that police were routinely stationed at the entrance of every hospital complex.

15. To some observers, the turning point for the reforms incorporating more aspects of social security was the 2006 speech by Party General Secretary Hu jintao, where he introduced the notion of "harmonious society." Joe C. B. Leung and Yuebin Xi, China's Social Welfare, Cambridge, UK, Malden, MA, Polity Press, 2015

16. In $2015,982,443$ institutions of this kind were recorded. This figure includes 25,865 hospitals, 36,899 township health centres, 34,264 health centres in villages or groups of villages, 646,044 free clinics in villages or groups of villages, and 3,491 centres for epidemic illness prevention and disease surveillance. Source: National Bureau of Statistics of China, "Statistical Communiqué of the People's Republic of China on the 2014 National Economic and Social Development," op. cit.

17. This figure includes 2.82 million doctors and assistants, and 2.92 million accredited nurses. The official number of beds is 6.52 million, of which 4.84 million are in hospitals and 1.17 million are in health centres.

18. In 2015 there were 5.9 million beds, of which 5.5 million were allocated for elderly people. In total, there are 2.8 million elderly people staying at these establishments. National Bureau of Statistics of China, "Statistical Communiqué of the People's Republic of China on the $2014 \mathrm{Na}$ tional Economic and Social Development," op. cit. Care for the elderly will not be explored further in this paper.

19. This will be explained later in the paper.

20. These terms will be more precisely defined later in the paper. 
The literature on the Chinese healthcare system describes its development, its reforms, and the effects of these reforms, ${ }^{(21)}$ in particular the effects of introducing health insurance. However, very little has been written on the topic of violence, ${ }^{(22)}$ and even less on the emergence of digital technology as a solution to the inefficiencies of the Chinese health system.

In the first part of this paper I will outline the health system's evolution, from its institution in the post-Mao era to the present day, while also touching on the effects of the economic reforms. In the second part, I will focus on describing the key factors that have led to the rise in violence between medical staff and patients, and the government's attempts to introduce primary care centres as a new point of entry for the treatment process. In the third part, I present the effects of these reforms in their current state, and the solutions offered by the use of e-health, as well as the benefits and limits of that approach.

This paper draws upon materials such as press articles and official statements, regulatory texts, official websites, and scientific articles published in both English and Chinese. It also makes reference to interviews carried out in Shanghai and Beijing between March and December 2015. Among those interviewed were doctors at Tier 1,2, and 3 hospitals, health centres, hospital financial directors, hospital information systems directors, nurses, researchers at the Chinese Academy of Social Sciences (CASS) and Fudan University, and managers at consulting firms.

\section{The structure of the hospital network}

\section{In rural areas...}

Up until the 1980s, in rural areas the Chinese healthcare system was divided into three levels of treatment access. ${ }^{(23)}$ The first level was equivalent to free clinics in villages; the second comprised health centres for the township; the third was represented by the county hospital. (24) This was the structure that made up the public healthcare system for each community. Treatment was mostly guaranteed free of charge, but the quality of treatment was poor.

Between 1966 and the start of the 1980s, nearly every village community had access to a free clinic, corresponding to Tier 1. In these clinics, treatment was administered by local workers who had been given a few weeks of training and were known as "barefoot doctors." They provided preventive treatment, ambulatory care, and first aid.

The Tier-2 healthcare establishments had a more advanced level of equipment than the free clinics or the township health centres. They dealt with patients who suffered from more serious illnesses. Patients were sent to these establishments when their condition required it.

Tier-3 hospitals were at the district level. Their purpose was to deal with more serious conditions, and they were better-equipped than Tier-2 establishments. They were also staffed by more senior personnel. Beyond this, there existed yet larger hospitals with even higher grades of equipment. These hospitals operated at the provincial or national level.

As highlighted by Therese Hesketh and Wei Xingzhu, (25) and also by Winnie Yip and William C. Hsiao, (26) between the 1950s and the start of the 1980s the structure of China's healthcare system allowed the country to make clear improvements to the health of its population. A number of indicators (presented in the introduction) attest to this. However, the level of care available was relatively low, using equipment of mediocre quality.
From 1991 onwards, the Chinese government promoted the creation of private organisations. The services provided by these private establishments were, overall, of a higher quality than those offered by public healthcare establishments. With the advent of economic reforms and decollectivisation (at the beginning of the 1980s), the people's communes that funded public services were dismantled. The community medical system found its funding cut dramatically, and sometimes this funding even disappeared completely. Existing public establishments were either replaced by private ones, or put into competition with them. As a result, Tier-1 public establishments began to collapse due to a lack of funding, leaving rural areas without public healthcare treatment. This meant that in rural areas, people had to cover a shorter distance to reach the nearest health centre, but in order to reach a public establishment they would have to travel further, as attested by John S. Akin et alii. (27) The overall effect of this was that, on average, local populations discovered that the sources of treatment on offer had become private, and more expensive.

At the same time, Tier- 2 and Tier-3 public healthcare providers acquired an increasing level of autonomy, including over the management of their profits. This allowed them to develop their equipment and acquire new medical technology. This was coupled with a rapid withdrawal of funding from the state and the provinces. (28)

Now that they had little or no public subsidy to rely on, public establishments were no longer subject to a duty of public service. Moreover, with public health establishments now behaving like commercial enterprises, economic theory dictated that the supplier should seek to maximise its profits. ${ }^{(29)}$ The fact that they had an effective monopoly over their local geographic area allowed public providers to set their own prices.

The price of healthcare (consultations, treatment, and medication) skyrocketed. This disruption to the treatment supply was paired with an in-

21. John S. Akin, William H. Dow, Peter M. Lance and Chung-Ping A Loh, "Changes in Access to Health Care in China, 1989-1997," Health Policy and Planning, Vol. 20, No. 2, 2005, pp. 80-89; Sarah L. Barber and Lan Yao, "Development and Status of Health Insurance Systems in China," The International Journal of Health Planning and Management, Vol. 26, No. 4, 2011, pp. 339-356; Meng Qingyue and Tang Shenglan, "Universal Health Care Coverage in China: Challenges and Opportunities," Procedia - Social and Behavioral Sciences, Vol. 77, 2013, pp. 330-340; Hufeng Wang, "A Dilemma of Chinese Healthcare Reform: How to Re-define Government Roles?", China Economic Review, Vol. 20, No. 4, pp. 598-604; Hufeng Wang, Michael K. Gusmano, and Qi Cao, "An Evaluation of the Policy on Community Health Organizations in China:Will the Priority of New Healthcare Reform in China be a Success?", Health Policy, Vol. 99, No. 1, 2011, pp. 37-43; Hong Liu, Song Gao, and John A. Rizzo, "The Expansion of Public Health Insurance and the Demand for Private Health Insurance in Rural China," China Economic Review, Vol. 22, No. 1, 2011, pp. $28-41$.

22. Xinging Zhang and Margaret Sleeboom-Faulkner, "Tensions between Medical Professionals and Patients in Mainland China," Cambridge Quarterly of Healthcare Ethics, Vol. 20, No. 3, 2011, pp. 458-465; Xu Xin and Lu Rongrong, "Baoli yu buxinren: zhuanxing Zhongguo de yiliao baoli yanjiu: 2000-2006" (Violence and mistrust: Research on violence in medical treatment in transforming China [2000-2006]), Fazhi yu shehui fazhan (Law and Social Development), No. 1, 2008, pp. 82101; Therese Hesketh, Dan Wu, Linan Mao, and Nan Ma, "Violence against Doctors in China," The British Medical Journal Clinical Research, No. 345, 2012, pp. 1-5.

23. Xingzhu Liu and Junle Wang, "An Introduction to China's Health Care System," Journal of Public Health Policy, Vol. 12, No. 1, 1991, pp. 104-116.

24. This sanji zhi system is often translated as "county-township-village three-tier healthcare system."

25. Therese Hesketh and Wei Xingzhu, "Health in China: From Mao to Market Reform," The British Medical Journal, No. 314, 1997, pp. 1543-1545.

26. Winnie Yip and William C. Hsiao, "What Drove the Cycles of Chinese Health System Reforms?", Health Systems \& Reform, Vol. 1, No. 1, 2015, pp. 52-61.

27. John S. Akin, William H. Dow, Peter M. Lance, and Chung-Ping A Loh, "Changes in Access to Health Care in China, 1989-1997," art. cit.

28. Chinese Ministry of Health, Research Report on China National Health Accounts, Beijing, 2004; Winnie Yip and William C. Hsiao, "The Chinese Health System at a Crossroads," Health Affairs, Vol. 27, No. 2, 2008, pp. 460-468. See the section on how the establishments were funded for further details.

29. Profit maximization in perfect competition. 
crease in revenue, leading in turn to revenue inequalities. The differences in the quality of treatment on offer between the cities and countryside became more pronounced. In addition, there was no longer an obligation to pass through Tier- 1 organisations in order to reach tiers 2 and 3. De facto, the rural population found itself offered a choice of establishments at which to seek medical consultation.

As a consequence, the rural population developed a preference for establishments in urban areas, especially those that offered an excellent level of quality. This was also facilitated by greater mobility among a certain sector of that population: there was a rapid decrease in the proportion of rural residents within the total population, and a growing number of them began commuting and working further from home. One possible correlate of this phenomenon was a considerable improvement in the state of the roads, and because of those improvements, journey times were reduced. The population became progressively less reluctant to traverse long distances and spend hours, or even days waiting in line for outpatient treatment.

For financial reasons, the lack of healthcare access became a major problem, first for the most vulnerable among China's population, and then for an increasing proportion of rural dwellers. ${ }^{(30)}$ The introduction in 2003 of a public insurance system brought momentary respite, although it did not resolve the issue in any lasting sense. (31) Furthermore, this health insurance system only made minor inroads into the healthcare network. In fact, if patients went to a hospital outside their local area, the rural public insurance system penalised them with a lower reimbursement (or none at all) for treatment. ${ }^{(32)}$ Even now, repayments for consultations remain very low, meaning that patients and their families are usually prepared to relinquish them.

All this has meant that in recent years, the very best hospitals in urban areas were, and still are, forced to deal with significantly higher demand than was intended.

We can therefore clearly see that since the 1980s, the treatment system in rural areas has moved 1) from a decentralised, structured system where the patient had no choice in their treatment pathway, where quality standards were low, and where there was little or no inequality in terms of treatment access, to 2) a centralised, destructured system where patients are free to choose their treatment pathway and where demand is centred around the highest-quality hospitals in urban areas, creating a shortage of supply, where top-quality treatment is demanded as standard, where there are major inequalities in access to treatment, and where a sector of the rural population would be excluded from the system, if it weren't for the state's implementation of public health insurance.

\section{....and in urban areas}

In urban areas, from 1949 to 1980, access to treatment was largely organised by and within state-owned enterprises. ${ }^{(33)}$ Each enterprise managed access to treatment on behalf of its employees and their children, as well as setting up a pension in preparation for retirement. These enterprises were gargantuan in size, and their sheer scale made it possible to spread potential risks. Just as in rural areas, the system was extremely decentralised.

As far as healthcare establishments were concerned, each patient was cared for by the establishment that was affiliated to their enterprise. Then, according to the gravity of the patient's condition and the establishments' abilities to accommodate them, the patient would be sent either to a district hospital, a municipal hospital, or a provincial hospital. At the highest level was the central hospital.
With the advent of economic reforms, state enterprises were transformed into private or semi-private businesses. They were divided up. In urban areas, the dismantling of the great state enterprises led to a breaking-up of medical insurance into smaller-scale units. The collective aspect of social security was henceforth managed independently by each enterprise. As a result, it found itself weakened: enterprises that were now smaller in scale soon found they were struggling to fund their own social security. Two main reasons accounted for this: firstly, since the units were smaller, the insurance was supported by a smaller number of individuals; in addition, these units were now supposed to turn a profit without any support from the state. However, a portion of their profits was used to provide social security for their employees. Bankruptcies piled up and threatened to destabilise the whole system. Threatened with impending economic collapse, the government was forced to take action, and decided to relieve the enterprises of the financial burden that came with social security. At the same time, the government introduced a public form of social security. This was much less extensive than its previous incarnation, but had the advantage of at least existing, in contrast to the situation in rural areas. As a result, urban residents were subjected to a decline in quality within their social security system, while the overall structure was preserved.

With the economic reforms and the dismantling of the state enterprises, a certain number of hospitals that belonged to what had once been large enterprises were transformed into local hospitals and managed by the various health departments. They owed their existence to the reforms carried out since the 1980s and offered a level of quality that was often deemed substandard by the population, both in terms of the medical staff (whose doctors were less well trained than elsewhere) and in terms of the facilities available for treatment.

In 1989, a hospital accreditation system was created by China's Ministry of Health. This was an initial attempt at classification. Since the year 2000, a new list, divided into three levels (and three subsidiary levels) has been in place, as well as a supplementary level for hospitals judged to be at an "excellent" level. A distinction was also drawn between profit-driven establishments and their non-profit counterparts, as well as between public and non-public. (34) This classification was accompanied by policy that focused on government subsidies and the levels of taxation that these establishments would have to pay. The first level is reserved for the most basic infrastructure, while the third level encompasses the largest infrastructure.

Meanwhile, a proactive policy was introduced to increase the supply of primary healthcare. In France, this primary care would be equivalent to a consultation at a doctor's surgery in a town, ambulatory care, or treatment

30. Carine Milcent, "Healthcare-seeking Behaviour Changes in Rural China:The Situation of Farmers," working paper, PSE No. 201423, 2015; Gerald Bloom and Gu Xingyuan, "Health Sector Reform: Lessons from China," Social Science and Medicine, Vol. 45, No. 3, 1997, pp. 351-360; Therese Hesketh and Weixing Zhu, "Health in China:The Healthcare Market," The British Medical Journal, No. 314, 1997, pp. 1616-1618; Jun Gao, Shenglan Tang, Rachel Tolhurst, and Keqing Rao, "Changing Access to Health Services in Urban China: Implications for Equity," Health Policy and Planning, Vol. 16, No. 3, 2001, pp. 302-312.

31. In rural areas, the public health insurance mentioned here is known as NCMS, or New Cooperative Medical Scheme.

32. Here we are referring to the period after the NCMS was introduced to the countryside.

33. In urban areas before 1979, a large proportion of healthcare establishments were built and managed by state enterprises, but not exclusively: there were also establishments at the provincial and municipal level (especially, but not limited to, People's Hospitals), as well as a number of military hospitals. The two systems coexisted.

34. State Council, "Implementing Guideline for Classified Administration on Urban Medical Institutions," 2000; State Council,"State Council General Office Notice to Issue the Instructive Opinions on Urban Medical and Health System Reform," 2000. 


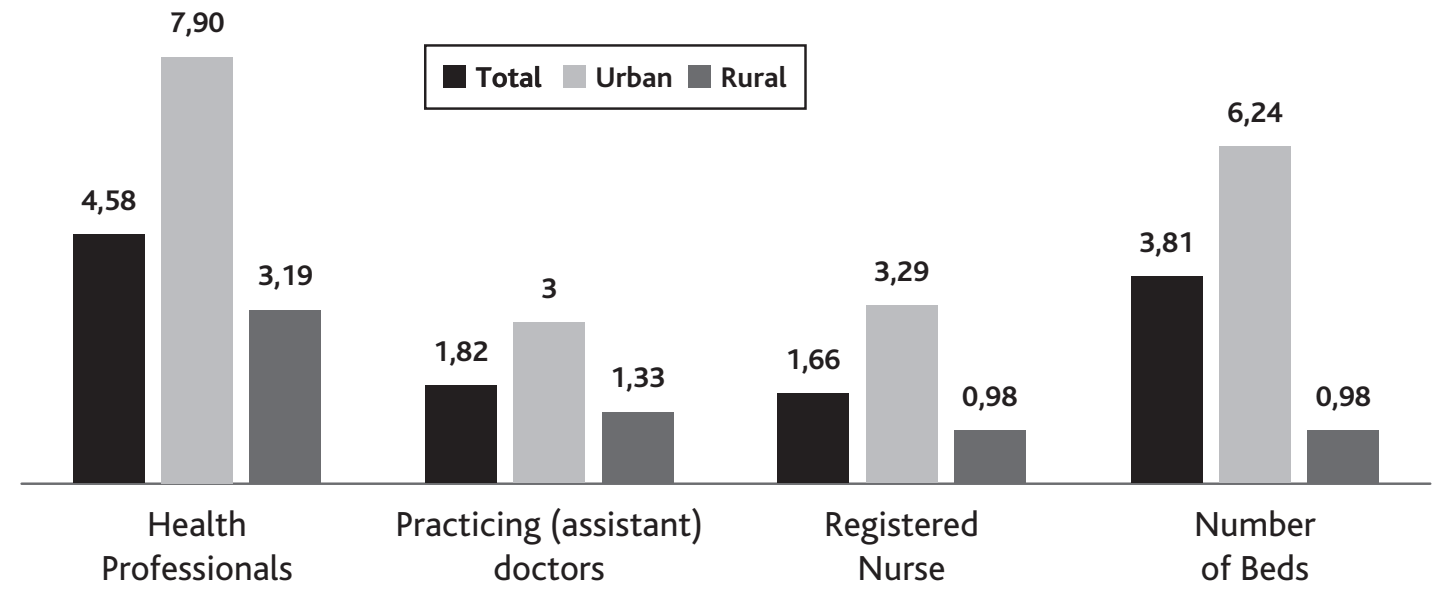

Source: Sarah L. Barber, Michael Borowitz, Henk Bekedam, and Jin Ma, "The Hospital of the Future in China: China's Reform of Public Hospitals and Trends from Industrialized Countries.", Health Policy and Planning, Vol. 29, No. 3, 2014, pp. 367-378. Figures from Chinese Health Statistical Yearbook (2012).

at a city health centre. These structures did not offer admission to hospital. For the Chinese government, the aim was to create consultation opportunities outside the hospital system. A certain number of Tier- 1 hospital centres were also converted into primary care centres.

To conclude this first part, the number of hospitals has now grown from 18,000 in 2003 to more than 25,000 . The majority of these (roughly twothirds) are public establishments. The hospital network is now being complemented by an ever-greater number of primary care centres. These include urban health centres, health centres in rural townships, and external consultation centres. In total, there are more than 900,000 care centre structures available. ${ }^{(35)}$

Behind these developments lie profound geographical disparities. The vast majority of care centres (72.2\%) can offer only rudimentary facilities and healthcare. Beijing, which is a province-level municipality, has five times more hospitals per capita (429 for a population of 10 million) than the province of Guangxi ( 88 for 10 million). Similarly, while the number of hospital beds has risen considerably since the 1960s, here too extreme disparities are found. ${ }^{(36)}$ Graph 1 illustrates the differences between urban and rural areas in terms of medical personnel and patient capacity.

In urban areas, we will also show how the structured, centralised system has developed into a system where demand is centred on the highest-achieving establishments. The series of reforms, including the major reforms of 2009, produced an increased supply of primary care facilities. However, people seem reluctant to choose this type of treatment pathway, and demand remains low. In short, it is possible to say that when we describe the supply of treatment available in China today, we are "talking about public hospitals."

\section{Yinao or violence within hospitals}

Yi 医 (medical) nao 闹 (argument/violence): each year, more than 10,000 doctors are estimated to be attacked. In 2010 the number of disputes rose to 17,243 cases, a $70 \%$ increase when compared to 2004 . According to one 2012 report, ${ }^{(38)}$ the rate of clashes between healthcare staff and families is increasing by $22.9 \%$ per year. One survey, carried out across ten provinces, found that half of all Chinese doctors have been the object of verbal attacks, while one-third have been physically threatened. ${ }^{(39)}$
We have seen how the Chinese health system has been destructured and how demand has become concentrated around first-rate hospital establishments. But how can we explain the fact that this destructuring and centralisation creates inefficiencies that give rise to a situation where violent acts are becoming more numerous and more pronounced? What are the key reasons for this rise in violence? I identify three main points, which are i) the previously-mentioned overwhelming demand for public establishments and the consequences thereof, connected to the changing public status of healthcare establishments, as well as ii) the specificities of Chinese public hospitals and the financial perks for doctors, and iii) the fact that doctors have a dual-status as both civil servant and cadre of the Party (bianzhi 编制) ${ }^{(40)}$ with all that that implies.

\section{Inefficient distribution of demand and its consequences}

While the supply of community health centres (CHCs) offering primary care has massively increased within the space of a few years, Tier-3 hospitals offering a higher level are seeing an ever-greater number of outpatients for consultation, and even more are being admitted to hospital. Between 2007 and 2011, the number of admissions grew by $56 \%$, and hospital consultations by $33 \%$. Graph 2 displays the changing number of hospital admissions and consultations between 1993 and 2012.

35. Swedish Agency for Growth Policy Analysis, "China's Healthcare System: Overview and Quality Improvements," 2013.

36. Source MoH, China National Health Yearbook 2009.

37. China Health Statistics Yearbook, 2012.

38. Wang Zhongming and Li Jianhua, "Yiliao jiufen fasheng de yuanyin ji yingdui cuoshi" (The reason and countering measures of medical disputes), Zhongguo shequ yishi (Chinese Community Doctor), No. 12, 2012, pp. 409-410, www.cnki.com.cn/Article/CJFDTotal-ZCSQ201212402.htm (accessed on 31 October 2016).

39. "Meinian yiwan yisheng bei ouda, cuiruo yihuan jinbuqi zhongya, baoli shang yisheng heshixiu" (Every year ten thousand doctors are attacked, the fragile doctor-patient relationship cannot stand the heavy burden of attacks, when will the violence stop?), health.people.com, 11 November 2011, http://health.people.com.cn/GB/16209592.html (accessed on 6 October 2014).

40. In the strictest sense, the term "civil servant" translates as gongwuyuan, but bianzhi encompasses much more than that. 


\section{Graph 2 - Changes in admission and consultation figures at public hospitals (1993-2012)}

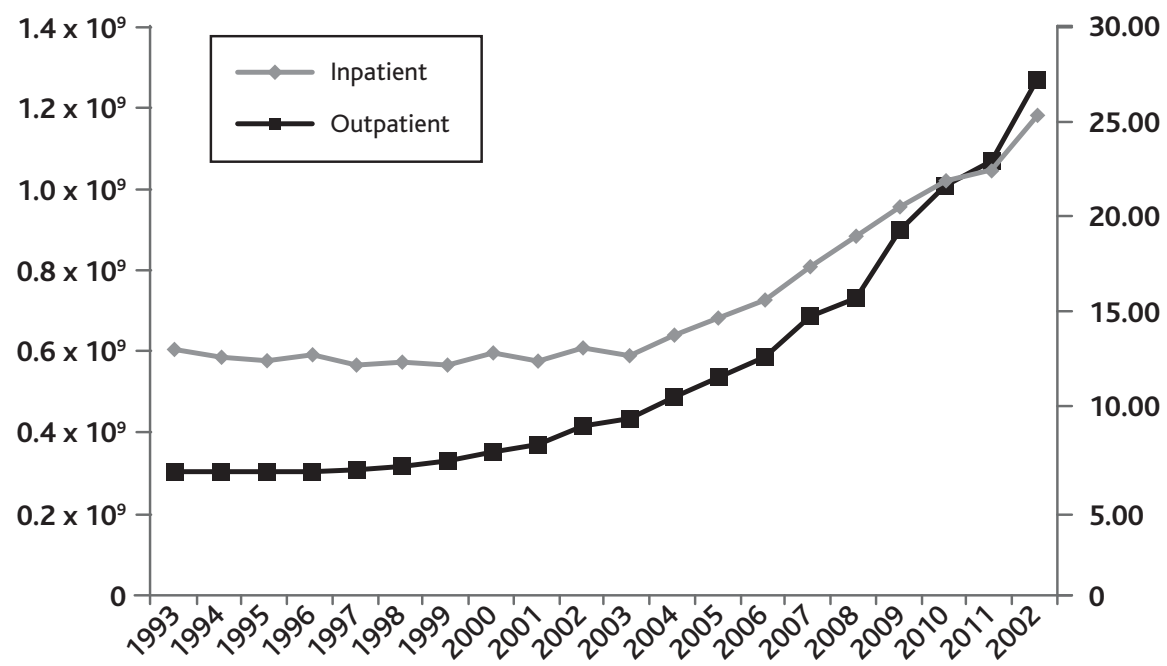

Source: Shan Wang, Lihua Liu, Lin Li, and Jianchao Liu, "Comparison of Chinese Inpatients with Different Types of Medical Insurance Before and After the 2009 Healthcare Reform," BMC Health Services Research, Vol. 14, No. 443, 2014. Figures from Chinese Health Statistics Yearbook (2012).

However, in interviews with doctors working at Tier-3 "excellent" grade hospitals (also known as 3AAA) and with patients at the aforementioned health centres, one regularly hears the same responses.

It is better to queue up in a hospital that can provide quality healthcare than to visit a more local centre, which is on a more human scale but does not offer the desired quality of treatment. In any case, Tier-3 hospitals provide an "all-in-one" option that $\mathrm{CHCs}$ and Tier-1 hospitals cannot offer, due to their fragmented nature. ${ }^{(41)}$

This means that now, it is fair to say that public hospitals cover the vast majority of medical outpatient consultations and hospital inpatient admissions. Across China as a whole, public hospitals account for $89 \%$ of the total number of beds, $91.6 \%$ of all admissions, and $91.7 \%$ of all outpatient consultations. ${ }^{(42)}$ According to one survey, $20 \%$ of patients who receive hospital consultations are suffering from colds or gastroenteritis. ${ }^{(43)}$

This situation has dramatic consequences on healthcare spending. It is estimated that $30 \%$ of admissions are medically unjustified. The cost of an admission is calculated to be 37 times more than that of a consultation. Furthermore, in China the length of a hospital stay is twice as long as the average time recorded among OECD nations. ${ }^{\left({ }^{44)}\right)}$ Although this is only an average figure, statistics such as these are worrying because they account for such a significant portion of healthcare expenditure. Certainly, this increased demand can be explained by the urbanisation of the population, but not by that alone: as explained previously, many people in rural areas are also driven to seek treatment at the top-ranked hospitals, for outpatient care as well as inpatient care.

When public health insurance was introduced in rural areas in 2003, one of the benefits could have been a redesigned pathway to treatment; but the implementation of this public insurance system was determined at the establishments where treatment was provided.

In both rural and urban areas, the introduction of various forms of public health insurance helped to reduce patients' out-of-pocket expenditure (the amount the patient has left to pay that is not covered by health insurance).
Between the 1990s and the present day, the percentage of outstanding charges has decreased in relation to total expense. According to a report by the World Health Organisation (WHO), ${ }^{(45)}$ in 1995 the figure was $46.4 \%$, then rose to $59 \%$ in 2000 , and now stands at $34.9 \%$ (Graph 3). However, on one hand, this figure does not take into account the significant geographical inequalities, particularly between city and countryside. On the other hand, at the same time there has been a considerable increase in expenditure, both as a percentage of GDP (from $4.55 \%$ in 2006 to $5.15 \%$ in 2011) (46) and per capita. This expenditure went from 178 RMB in 1995 to 362 RMB in 2000 , and now stands at 1,801 RMB. The result of this is that, despite an appreciable improvement in health insurance coverage, the outstanding charges have risen considerably.

As such, the range of treatments covered and the level of cover were, and remain, extremely limited. (47) These measures were not sufficient to cope with the geographic upheavals among the patient base. There was higher demand among those seeking quality treatment, and who were willing to sacrifice accessibility in both geographical and financial terms. Free clinics, primary care centres, and Tier-1 hospitals were shunned in favour of Tier-2 and especially Tier-3 hospitals. Another consequence of this concentrated demand was that Tier-3 hospitals became overburdened, leading to incredibly long queues and very short consultation times. The situation was exacerbated all the more by the fact that these establishments were able to offer highperformance equipment and quality treatment. At the same time the primary care centres, along with Tier- 1 and a number of Tier-2 hospitals, found their range of facilities, including their equipment, were being underused. The proportion of beds in use was above $100 \%$ in the top-ranked hospitals, while it was at $80 \%$ in Tier-2 establishments, and $55 \%$ in Tier- 1 establishments. ${ }^{(48)}$

All this occurred with a large proportion of the population in a situation of financial instability. With expenditure increasing rapidly, making health-

41. Interview in Beijing, November 2015 (translated from Chinese)

42. Sarah L. Barber, Michael Borowitz, Henk Bekedam, and jin Ma, "The Hospital of the Future in China: China's Reform of Public Hospitals and Trends from Industrialized Countries," Health Policy and Planning, Vol. 29, No. 3, 2014, pp. 367-378. Figures from Chinese Health Statistical Yearbook, 2012.

43. Lim Meng Kim, Yang Hui, Zhang Tuohong, Zhou Zijun, Feng Wen, Chen Yude, "The Role and Scope of Private Medical Practice in China," Final report to the World Health Organization and the United Nations Development Programme, UNDP, WHO and MOH China, 2002.

44. World Bank, "Urban China:Toward Efficient, Inclusive, and Sustainable Urbanization," Development Research Center of the State Council, source MoH, 2011

45. Shyama Kuruvilla, Julian Schweitzer, David Bishai, Sadia Chowdhury, Daniele Caramani, Laura Frost, Rafael Cortez, Bernadette Daelmans, Andres de Francisco, Taghreed Adam, Robert Cohen, Y Natalia Alfonso, Jennifer Franz-Vasdeki, Seemeen Saadat, Beth Anne Pratt, Beatrice Eugster, Sarah Bandali, Pritha Venkatachalam, Rachael Hinton, John Murray, Sharon Arscott-Mills, Henrik Axelson, Blerta Maliqi, Intissar Sarker, Rama Lakshminarayanan, Troy Jacobs, Susan Jacks, Elizabeth Mason, Abdul Chaffar, Nicholas Mays, Carole Presern, Flavia Bustreo, "Success Factors for Women's and Children's Health Study Groups," Bulletin of World Health Organisation, Vol. 92, No. 7, 2014, pp. 533-544. www.who.int/pmnch/successfactors/en (accessed on 31 October 2016). The source data are drawn from the China Health Statistics Yearbook.

46. China Health Statistical Yearbook, 2012.

47. Carine Milcent and Binzhen Wu "How Do You Feel? The Effect of the New Cooperative Medical Scheme in China," The Journal of Development Studies, Vol. 51, No. 12, 2015, pp. 1585-1602.

48. Claudia Süssmuth-Dyckerhoff and Jin Wang, "China's Health Care Reforms," Health International, No. $10,2010$. 


Distribution of
healthcare
expenditure as
a percentage of total
health expenditure
(THE)

Private Health Insurance
and Extra-Budgetary
General Government
Expenditure on Health
(GGHE) as \% of THE
Out of Pocket Expenditure
as \% of THE
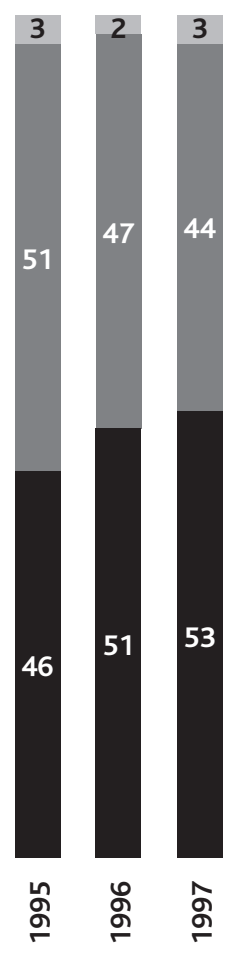
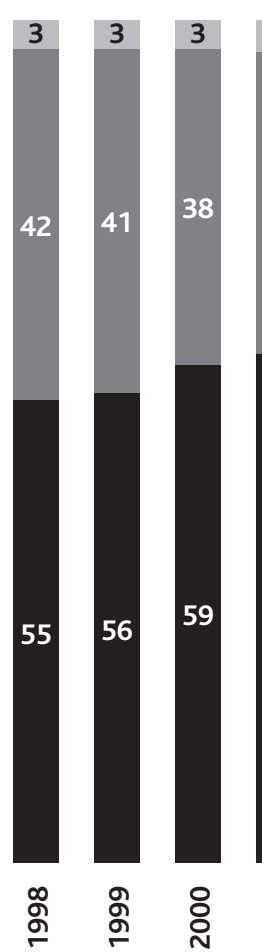
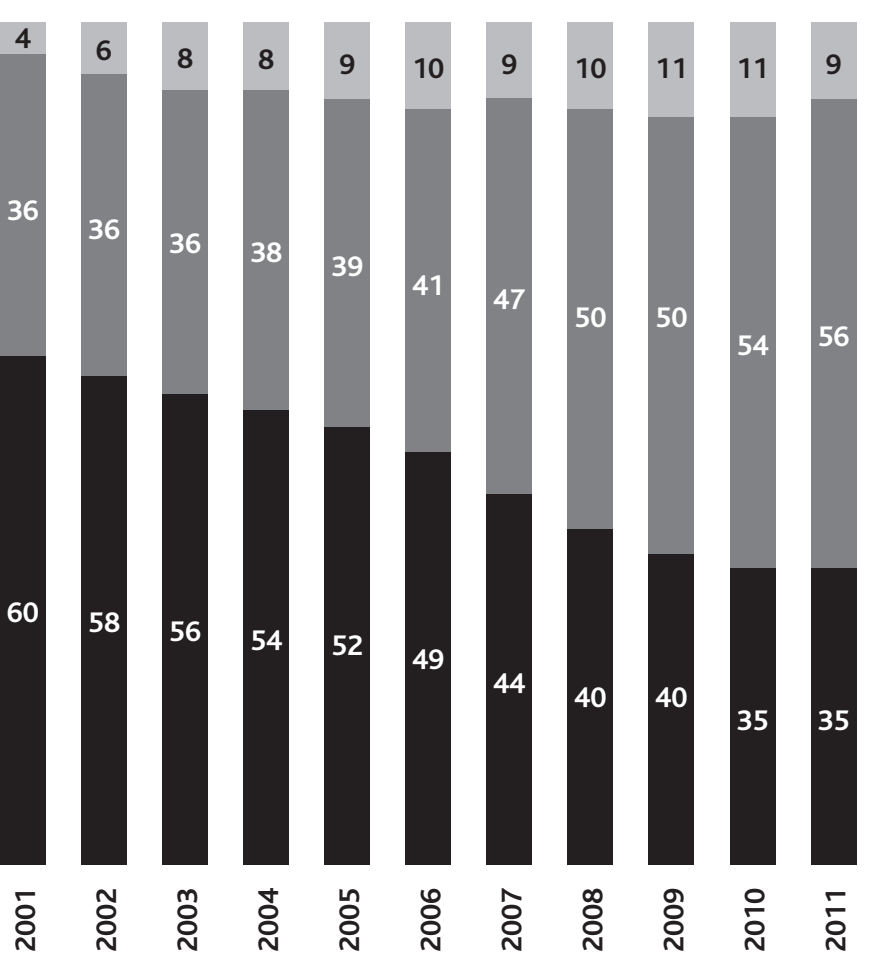

Source: World Health Organization database, http://apps.who.int//nha/database (accessed on 31 October 2016). The data sources come from China Health Statistics Yearbook (2012).

care less financially accessible, this gave rise to a certain amount of tension between patients and medical staff at the top-ranked hospitals.

\section{Waiting time management as a factor in increased tensions between patients and medical staff}

The website of Beijing Hospital (北京医院), one of Beijing's largest hospitals, claims that the establishment gives 4,500 medical consultations every day. According to the same source, that translates to between 60 and 80 consultations per doctor per day. When the hospital is held in high regard, this figure can reach as many as 100 patients per doctor per day, and even up to 200 on peak days. ${ }^{(49)}$ The Anzhen Hospital received more than 2.41 million patients for consultations in 2014. Within the region, it is one of the ten hospitals that provide the greatest number of consultations. At the Beijing Children's Hospital, the number of outpatient consultations reached 3.37 million in 2014. According to one doctor at a hospital in Shanghai, (50) "Now, it is not uncommon to see more than 1,000 patients and family members waiting in the early hours of the morning."

In the hospitals that I visited, doctors regularly mentioned appointment times of two minutes per patient. According to a study carried out in Shaanxi Province, doctors there spend less than a minute and a half speaking with the patient. This can sometimes result in hysterical behaviour on the part of patients and their families.

By visiting Chinese hospitals it is possible to better understand how outpatient consultations are managed. The hospital is divided into two sections. The section dedicated to outpatient consultations is located in an enormous entrance hall. At its centre is a reception area manned by nursing staff. Their role is to direct the patient to the appropriate specialist. However, the num- ber of available nursing staff means that it is not possible to deal with every request for information. During the course of a group discussion at a large hospital in Beijing, one doctor explained:

It is impossible to manage the constant flow of patients, because there are so many of them. This means that the patients themselves are forced to choose the appropriate area of expertise for their consultation. The patient is supposed to take a numbered ticket. They are then registered as requiring an outpatient consultation. Then they must go directly to the prepayment counter to validate their entry on the outpatient consultation list. This system creates a lot of frustration for people. ${ }^{(51)}$

Among these frustrations, two types are especially significant. Firstly, the lack of general practitioners means that the patient cannot always be certain which specialist they should consult. Their waiting time to receive a ticket, then to consult with a specialist, is made even more difficult by the lack of certainty that they have chosen the right person.

Secondly, another consequence of such intensive demand is that a black market for selling tickets has developed. Even though taking a ticket to wait in line incurs a cost, the amount is so negligible that it provides no disincentive to trading tickets, particularly at Tier-3 establishments. One example of this can be found at one of Beijing's best-equipped hospitals, Peking Uni-

49. Interview in Beijing and Shanghai with doctors at Tier-3 hospitals, February, November, and December 2015.

50. Xinhua, "No More Long Queues in China's Smart Hospitals," China Daily, August 2015, www.chinadaily.com.cn/china/2015-08/05/content_21511189.htm (accessed on 14 September 2016).

51. Interview in Beijing, November 2015 (translated from Chinese). 
versity Renmin Hospital (Beijing daxue renmin yiyuan 北京大学人民医院), where tickets cost 5 RMB each and only a limited number are distributed each day. On the black market the price of these tickets can soon soar as high as 200 RMB, or even beyond that, further adding to the cost of a consultation. Taking into account waiting times that can extend up to several days, extremely short consultation times, and the black market for tickets, it is easy to understand the sense of frustration, or even anger among patients, which can drive them to commit violent acts. Added to this is the practice of "red envelopes": bribes handed to hospital staff, including doctors, as another way of cutting waiting times, as well as ensuring better care for patients in the event that they are hospitalised. (52)

\section{Funding methods for establishments and personnel as a causal factor in the rise of violence}

Generally speaking, at the start of the 1980 s, the state funded $60 \%$ of the spending in hospital establishments. By 2003, this funding had shrunk to an average of $7 \%$. In the period from 1979 to 1991, the government introduced a co-payment system for healthcare establishments. The aim of this was to offer greater flexibility in terms of profit, and thereby to encourage establishments to improve their quality of treatment and increase the professional standards of their medical staff. (53) In order to cope with the shortfall in funding, healthcare establishments turned to medication and diagnostic procedures as their main source of income. In 1992, the Ministry of Health officially granted greater autonomy to all public hospitals, allowing them to charge for their services and sell them at a profit. They were responsible for their losses and debts, but in return they keep any surplus generated by their business. They self-funded a large part of their investments in equipment and infrastructure. They could also join forces with private organisations to create joint ventures, as well as invest in a profit-driven healthcare department within the structure of the public hospital itself.

Public hospitals in China now have the distinguishing feature that, like other businesses, they are supposed to maximise their profits by choosing investments and fixing prices, while simultaneously retaining the traditional governance structure of a public institution. For example, funds allocated by the state or by local authorities are granted exclusively to public hospitals. ${ }^{(54)}$ Additionally, managing staff is the responsibility of the central public sector authorities, in particular the Ministry of Human Resources and Social Security (MOHRSS): it is they who determine how the workforce is structured and who gets promoted. The connection between the central powers and hospital organisations still exists, despite the hospitals' autonomy. Hospitals still have an effective monopoly over their geographic region, which leads to a lack of competition and therefore a lack of price regulation by the market. When the cost of treatment is fixed by the hospital organisation, with no regulation (from either administration or the market), this can create a problematic situation. So, in summary, public hospitals have an incentive to increase their revenue by providing increasingly expensive (and therefore profitable) treatments, without any regulatory framework (either by the market or by the state or the provinces). ${ }^{(55)}$

Moreover, given the way that public hospitals currently operate (as described earlier), doctors and hospital staff can also receive supplementary income via a series of opaque rules. This supplementary income is reliant on the public establishment's activity as a profit-making business. It is therefore easy to understand why doctors might be encouraged to take steps to increase their most lucrative practices: increasing the number of appoint- ments, over-prescribing, over-diagnosing. Consequently, the "operational objective" for treatment personnel and for doctors includes maximising profits. Within this setup, both parties benefit: not only the hospital management but also the medical staff. An occupation in which remuneration was, until now, disconnected from any profit-driven influence becomes a race for financial gain. Today, medical drug sales make up over $40 \%$ of turnover for public health establishments. It is the patients who suffer, with the cost of healthcare increasing drastically in parallel with the overconsumption of treatment, creating a climate of ever-growing tension between medical staff, doctors, and patients.

\section{Why is it difficult to decentralise the supply of quality treatment that is causing these tensions?}

There are approximately 2.79 million (registered) doctors practising in China, $90 \%$ of whom have received training in Western medicine, rather than exclusively in traditional Chinese medicine. The training process for doctors in China is relatively complex and varies according to geographical region. In 2013 , only $28.5 \%$ of the treatment on offer in hospitals was provided by staff who had received at least degree-level training. ${ }^{(56)}$ In rural areas, 70\% of the medical and treatment staff had gained no further qualifications since secondary school. (57) Theoretically, a "rural" doctor would not be able to practice in an urban area, because his level of training would be too low. That said, the doctor's seniority could also be taken into account.

While doctors at Tier-2 hospitals are increasingly qualified with higher education degrees, many of them still leave with training that is roughly equivalent to taking a specialist subject at sixth-form. By contrast, the doctors at Tier-3 health establishments are educated to university level, and are increasingly able to benefit from continuing education. This situation is constantly evolving. After obtaining a degree, young doctors become employees of the establishment where they find a post. If they obtain a post at a Tier-3 public hospital, they are also granted the status of civil servant (bianzhi). This status applies not only to doctors but also to a large section of the medical staff, guaranteeing a job for life as well as other benefits in terms of medical supervision and retirement. In addition, this marks the beginning of a double career: on one hand, the doctor progresses within the hospital structure, while on the other also progressing within the Communist Party, the two careers mutually supporting one another.

Furthermore, one condition of gaining bianzhi status is that today, medical staff working in hospitals do not have the option of working simultaneously for another organisation, either in the same locality or elsewhere. Their professional registration number is linked to a medical structure. For a doctor

52. Cheris Shun Ching Chan, "A Market of Distrust: Unofficial Payments for Hospital Care in China," The 12th Conference of the European Sociological Association (ESA 2015), Prague, Czech Republic, 25-28 August 2015

53. Juan Du, "Economic Reforms and Health Insurance in China," Social Science and Medicine, Vol. 69, No. 3, 2009, pp. 387-395,

54. Although examples to the contrary do exist on a small scale.

55. The purpose of the 2009 reforms was to force hospital establishments to change this situation. However, they have had only a minor effect.

56. "China Releases 2013 Health and Family Planning Statistics," China Daily, 25 June 2014, http://en.nhfpc.gov.cn/2014-06/25/content_19004549.htm (accessed on 19 January 2016); The same year, the number of registered doctors reached 2.06 per thousand, the number of registered nurses reached 2.05 per thousand, and the number of beds reached 4.55 per thousand.

57. Chuji zhongxue translates as "junior high school". Karen Eggleston, Li Ling, Meng Qingyue, Magnus Lindelow, and Adam Wagstaff, "Health Service Delivery in China:A Literature Review," Health Economics, Vol. 17, No. 2, 2008, pp. 149-165. 
who has civil servant status, deciding to work within a private structure would therefore mean losing this status, with no possibility of getting it back.

As a consequence, it is extremely difficult for private structures to recruit doctors with the very best qualifications. The status of doctors, the benefits that come with this status, and the various forms of supplementary income create a significant disincentive to working within a private structure. ${ }^{(58)}$ Over a given geographic region, this therefore has a powerful limiting effect on the possibility of competition: only the public sector remains attractive, due to the quality of its medical personnel. However, one of the experimental aspects of hospital reform has been the possibility for practitioners to operate within another structure than the one where they are professionally registered. According to researchers at CASS and at Fudan University, ${ }^{(59)}$ while in theory the reform makes this possible, in practice doctors are discouraged from such behaviour by their hospital's management and administration. The measures used to deter them include a reduction of doctors' bonuses, along with reductions to other supplementary income and a potentially harmful effect on their career progression. ${ }^{(60)}$

Beyond the effects on finances and status, there are other, secondary consequences. The lack of highly-regarded doctors available to work in private structures leads these structures to hire less talented doctors, thereby engendering further rejection of these establishments, both by promising young doctors and by the patient base. An Hua and Li Peng, two doctors at a top-ranked hospital in Beijing, would not be opposed to going to work within a private structure. ${ }^{(61)}$ They said that their working hours, the number of patients, and the toxic atmosphere between patients and medical staff at their current workplace was a considerable burden on them both. However, they were not aware of any private structure that was able to offer them a team of sufficient size, or a stimulating working environment.

As a result, there is a strong correlation between highly-trained teams of doctors and first-class hospitals, although there remains a certain amount of variance. For a patient base that is not fully acquainted with the staff distribution of each healthcare structure, going to a highly-ranked hospital is one way of ensuring they are treated by a "reliable medical team."

University think-tanks make a case for the idea that questioning bianzhi status among medical staff could help to reintroduce a sense of motivation. According to Hengpeng Zhu, Deputy Director at the Institute of Economics and Head of Public Policy Research at CASS, bianzhi status has a negative effect on the efficiency of medical establishments. He also suggests that this status should either be modified, or only used in limited circumstances. ${ }^{(62)}$

To conclude this part, as explained previously, patients are almost exclusively concentrated around large hospitals (Tier-3 or 3AAA), which are also the hospitals with the best quality equipment. Doctors at these hospitals must i) cope with the influx of patients who prefer to visit these establishments and ii) look after their patient base while simultaneously maximising the cost of consultation.

All this occurs within an environment where information is in limited supply and the patient cannot judge for himself or herself whether their treatment and prescriptions are appropriate.

\section{The contribution of digital technology and "virtual healthcare"}

On the one hand, we see the inefficient geographical distribution of supply, creating medical "deserts" within Chinese territory; on the other, we see the inefficient geographical distribution of demand, leading to overcrowding at Tier-3 hospitals through disorganised or misused primary (ambulatory) care facilities: all of which points to digital technology as a potentially appealing solution, allowing supply to connect with demand, regardless of physical location. In this part we will see some of the innovative solutions that have been put forward.

The Chinese health system currently finds itself in a situation where there is little or no oral communication or dialogue between the treatment supply and the treatment demand. An atmosphere of mistrust has replaced the doctor-patient relationship that existed before the 1980s, even with doctors who had only a basic level of training. Time was a less important factor. Today, the time allotted to patients by doctors with a "Western" style education (63) (that is, five or more years of study after high school) is too short, since these doctors are mostly located in Tier-3 hospital establishments where consultation times are now less than two minutes. At the same time, doctors who have less training but are still sufficiently qualified to deal with a large part of the demand for primary care, do not encounter said demand. Added to that is an increase in patient's out-of-pocket expenditure ${ }^{(64)}$ while the doctors receive financial compensation in correlation with the rate of healthcare expenditure. All this leads to a dynamic of conflict between hospital personnel and the patients or their loved ones, which can sometimes culminate in extremely violent behaviour. We will see how the Internet can be used as a first step in responding to some of the Chinese health system's inefficiencies: for instance, greater communication through online advice and communication, and telemedicine, which provides access to qualified doctors, even in medically "deserted" areas. Furthermore, the means by which establishments and doctors are funded is one of the key factors in the current conflictual relationship. One way to effect change is to introduce alternative payment models, limiting the incentive to over-prescribe or over-diagnose. The funding method that seems most suited to achieving these objectives is one that first appeared in the United States, based around groups of related illnesses. The generic term is Diagnostic Related Group (DRG). It requires large quantities of high-quality information on the medical aspect of the patient's stay, including pathology, diagnoses, procedures performed during the stay, and length of stay. Such a DRG-basis funding method depends on the implementation of a performing database system of information.

\section{The Internet as a tool for professionals, helping to distribute the supply of "excellent" healthcare}

As we have seen, the expectations in terms of quality have visibly changed since the economic reforms of the 1980s. Patients or their families are willing to travel many miles for a consultation at a hospital establishment that meets these expectations, which leads to the oversaturation of services. Digital technology offers a solution to this by, on the one hand, allowing greater virtual communication between professionals and helping to distribute medical

58. See section on bianzhi.

59. Interviews in Beijing and Shanghai, October and November 2015 (translated from Chinese and English).

60. Interviews in Beijing and Shanghai, November 2015 (translated from Chinese).

61. Interview in Beijing, June 2015 (translated from Chinese). The doctors' names have been changed.

62. Interview in Beijing, November 2015 (translated from Chinese).

63. This is not an attempt to place Chinese and Western medicine in opposition to one another. The relevant difference here is in the length of medical training and the educational process required to become a doctor of medicine.

64. These outstanding charges are measured by the total amount payable, and not by the percentage of total healthcare expenditure. 
knowledge; and on the other hand, making use of the virtual realm to facilitate clinical collaboration (as in the case of telemedicine described below).

Firstly, there is the Clinical Decision Support System, a tool that helps practitioners avoid medical errors. It provides warnings about side-effects, allergies, and other undesirable consequences. Initially introduced in the 1990s, it is now used in only a minority of cases. The sudden escalation in smartphone use has allowed for greater flexibility when it comes to accessing these assistance tools. There are now applications and platforms that give professionals online access to research papers, such as the platform introduced by Ding Xiang Yuan in 2000. Today, more than 880,000 doctors consult the platform. Doctors are also modifying their prescription habits, based on information available via the Internet.

Another more effective means of helping professionals is also made possible thanks to telemedicine. The concept of telemedicine was introduced in 1999, in a circular from the Ministry of Health, encouraging two healthcare institutions to use it as a communication tool. By 2013, according to statistics published by the NHFPC (National Health and Family Planning Commission of the People's Republic of China), 2,057 medical institutions were using this type of method. On 29 August 2014, the NHFPC published guidelines regarding telemedicine services in China. These documents were soon made public. ${ }^{(65)}$ In them, the opinions put forward promoted a more intensive use of telemedicine by medical institutions. They reflected efforts by the Chinese government to bring telemedicine into general use all over the country. Telemedicine was seen as a tool that could resolve, at least in part, the geographical disparities that existed. And so, to deal with these physical, geographical difficulties, a digital solution was put forward.

\section{Using the Internet to eliminate the black market for waiting line tickets}

The Internet, along with mobile phone applications, can also be used to regulate and channel demand, in order to reduce oversaturation at Tier-3 hospitals. In Beijing, the Municipal Commission of Health and Family Planning confirmed in December 2015 that by the end of 2017, all first-class hospitals would require their patients to make appointments online, and would also offer the opportunity to pay online, in order to reduce the need for queuing on site. This payment method has already been introduced in a number of Beijing hospitals. For example, since June 2015, one of Beijing's largest hospitals, the Beijing Children's Hospital (Beijing ertong yiyuan 北京 儿童医院), has given its patients the option of making an appointment online, as well as paying online, via an app for mobile phones. Certain hospitals are even extending their virtual services, using them to send out test results.

We have seen how one effect of excessive demand around Tier-3 establishments is an increase in waiting times. In such cases, the Internet would appear to be an obvious way to mitigate the need to physically wait in line. However, it does not reduce the total time spent waiting for a medical consultation or hospital admission, and the Internet should therefore be considered only one solution among many.

\section{The Internet as a new healthcare supply market}

As previously explained, a major proportion of patients are deeply mistrustful of treatment provided by doctors who do not work within the topranked hospital organisations. Since a doctor's medical practice is intrinsically connected to a hospital, there is a sense in which they "belong" to that hospital. Consequently, there is almost no mobility among "trained and qualified" doctors. However, a grey area does exist in the form of consultancy. According to a legal researcher at CASS, ${ }^{(66)}$ the status of "consultant" falls under a judicial grey area that allows doctors to work outside their own hospital organisation. This means that a doctor who belongs to a given hospital can offer consultations virtually via the web, without undermining the principle of working within a single medical practice. Offering consultations over the Internet can be considered simply as consultancy.

For patients, the most commonly used applications are the ones that offer online consultations. This is a way to avoid long queues in hospital and/or to receive a first or second opinion from a specialist who is practicing at a top-quality hospital. There are Internet platforms where doctors can offer advice based on information provided by the patient. One example of this is Chunyuyisheng, which numbers more than 15 million users and 10,000 fully qualified doctors. As far as supply is concerned, the development of digital healthcare has opened up new business possibilities for doctors, without requiring them to travel to another establishment. Their status as consultants means that doctors are not subjected to the consequences of carrying out a secondary business.

The benefit of the Internet, therefore, is that it gives patients access to doctors who can meet their desired standards, with consultations sometimes costing less than they would in a hospital (where "red envelopes" and the black market for tickets could further increase the face value of an appointment). Consequently, digital access to the treatment market seems to be gaining dominance over other forms of access promoted by the state, such as creating more primary health centres for consultations. However, the prescription and distribution of medication are obstacles to the digital realm. Currently, discussions are taking place about the creation of an association to bridge the gap between virtual consultations and the primary health centres that would provide a space for giving out medication. It would seem that, on one hand, the Internet makes it possible to resolve the problem created by lack of mobility among doctors at Tier-3 hospitals. On the other, the Internet creates a market in competition with these establishments, which until now held a monopoly over their geographical locality. There are also platforms allowing direct mobile communication between patients and doctors. During my visits to Beijing, I was able to test out WeChat, as well as e-mail, as a means of doctor-patient communication at several of Beijing's hospitals. The advantage is that, without having to travel, it is still possible to ask your doctor questions or request further information following a medical consultation. However, these services are not regulated, which poses issues of responsibility for the doctors practicing in this way. The question of data confidentiality is also a pertinent one.

\section{Digital technology and its contribution to a new funding method for hospitals}

We have seen the influence that funding methods for healthcare establishments can have on the conflictual dynamic between healthcare personnel and their patients. Here we will see how the Internet can intervene, by setting up a new payment method that is partly separated from the prescription and diagnosis process.

65. The views of the NHFPC and an English translation can be found at the following site: https://www.healthcarelawtoday.com/wp-content/uploads/sites/15/2014/09/ChinaTelemedicine-Opinions-Aug-29-2014.pdf (accessed on 31 October 2016).

66. Interviews in Beijing, October and November 2015 (in English). 
Internationally, there is widespread agreement ${ }^{(67)}$ on the advantages of a hospital pricing scale that is based on the establishment's activity, because this type of pricing helps to prevent over-prescription. China is no exception, and is also keen to implement the same pricing scale. ${ }^{(68)}$ However, this pricing system requires a complex information base, containing extremely exhaustive and standardised data. Hospital visits are classed with a code, depending on the actions taken and diagnoses made during the stay. Each code is linked to a price.

Another purpose of the reforms is to improve the health system's IT capabilities, which are, at the moment, comparatively basic. In 2012, the $\mathrm{MoH}$ invested $\$ 9.5$ million ${ }^{(69)}$ in developing methods for recording medical data and improving information systems in Chinese hospitals. The goal is to create data that are standardised, especially regarding the characteristics of the patients, in order to better respond to their needs and thereby limit the atmosphere of tension that is prevalent today.

The first phase set out by the Ministry of Health is to routinely collect, in a standardised manner, information that might be useful for supervising staff (and/or the paying agency), for healthcare providers, and (on an individual level) for the patient's medical file. One of the purposes is to obtain a wide-ranging collection of Electronic Medical Records (EMRs). In certain regions, such as Beijing, IT systems that use this same procedure have already been developed, and are being contributed to by several major university hospitals and other hospital structures. Other regions have also launched pilot projects to implement EMRs, such as the provinces of Jiangsu and Fujian. ${ }^{(70)}$

\section{Conclusion and discussion}

I have shown that patients' expectations have become higher over time. They have been increasingly demanding over what a "trained and qualified" doctor should mean. As a consequence, the actual, addressable supply has been shrinking, creating longer and longer queues coupled with shorter and shorter consultation times. In parallel, the price of treatment has spiralled upwards due the financial autonomy of hospitals, as the government has withdrawn its support and doctors have been incentivised to generate revenue through over-diagnosis and over-prescription.

What with skyrocketing costs, extreme waiting times, consultation time reduced to a bare minimum, added to rampant bribery throughout the system, the patient-doctor relationship has progressively become conflictive.

To address this situation, measures haven been taken to increase the number of public primary health centres and to encourage the development of the private sector in order to fuel competition among providers, or even to limit profit margins, for example by implementing "zero mark-up" policies on a list of essential medications. Yet, all of these have had limited impact. Digital technologies offer a promising route to develop innovative solutions to fix the current inefficiencies in the health system in China.

On the flip side, digital solutions also have their shortcomings. One of them is that this market is entrusted to a handful of giant private players. In order to achieve certain specific goals, the Chinese government made the decision to outsource certain public service tasks to profit-driven companies. There are therefore questions being raised about the potentially dominant position in which these firms could soon find themselves.

Concerns about these conflicts of interests have become increasingly prominent in the light of recent scandals. I will conclude this paper with some of these stories, focusing on three Internet giants (Baidu, Alibaba, and
Tencent), with an emphasis on the implications for the Chinese health system that is currently under construction.

The Baidu Tieba Forum, part of Baidu (the Chinese equivalent of Coogle), is an Internet forum administrator. It contains more than 10,000 sub-forums, including forums for exchanging healthcare information. In recent months, a number of scandals have erupted ${ }^{(71)}$ over the capacity for private companies to take control of these non-commercial forums, allowing ads for medical products of dubious quality. The flashpoint for this was the case of a forum on haemophilia (a blood disorder). It was displaying advertisements that extolled the virtues of healthcare providers that turned out to be unlicensed and of poor quality. More recently, in May of this year, a student who died of cancer had published a long post where he placed the blame squarely on Baidu for irresponsibly exaggerating the capabilities and quality of the hospital where he chose to have treatment.

The government has sought to implement a platform that would authenticate and track pharmaceutical products (Product Identification Authentication and Tracking System, or PIATS). (72) PIATS was outsourced by the China Food and Drug Administration to Ali Health, a division of Alibaba. Beyond the questions raised over a private, profit-driven enterprise collecting personal medical data, the company appears to be embroiled in a conflict of interest, in the sense that the company itself sells medication online (Alibaba announced that the running of online pharmacy Tmall Online would be transferred to Ali Health $\left.{ }^{(73)}\right)$. This gives Ali Health a major role in regulating healthcare products and privileged information on those very same products. ${ }^{(74)}$ PIATS management drew attention to the dual responsibility of taking part in the regulation of pharmaceutical sales while simultaneously operating within that market. To placate the other operators in that sector, it was announced that pharmaceutical companies will be exempted from drug tracking fees for a period of three years. But what lies in store after that? ${ }^{(75)}$

In conclusion, we can say that digital healthcare offers multiple sources of improvement but is not in itself a fully-fledged solution to fix all ineffi-

67. While there may be a consensus on this type of pricing scale, the methods of implementation are still subject to criticism within the countries themselves.

68. Peter Leslie Annear and Dale Huntington (eds), "Case-based Payment Systems for Hospital Funding in Asia: An Investigation of Current Status and Future Directions," OCDE, Asia Pacific Observatory on Health Systems and Policies, Comparative Country Studies, Vol. 1, No. 2, 2015.

69. Alison Tudor-Ackroyd, "Private Equity Backs China's Healthcare Push," FinanceAsia, 16 September 2015, www.financeasia.com/News/401984,private-equity-backs-china8217s-healthcarepush.aspx (accessed on 24 May 2016).

70. Claudia Süssmuth-Dyckerhoff and Jin Wang, "China's Health Care Reforms," art. cit.

71. Zhou Dongxu, "Baidu Backtracks on Letting Private Firms Run Popular Forums," CaixinOnline, 13 January 2016, http://english.caixin.com/2016-01-13/100899054.html; Belinda Cao and Stephen Stapczynski, "Baidu Retreats on Chinese Private Hospital Advertising Boycott," Bloomberg, 6 April 2015, www.bloomberg.com/news/articles/2015-04-06/baidu-retreats-on-chinese-private-hospital-advertising-boycott (URLs accessed on 31 October 2016).

72. The judicial situation is more complex, because the Citic $21 \mathrm{CN}$ company, which manages pharmaceutical product data, is also involved in setting up PIATS and is partially owned by Ali Health.

73. The relationship between the branches of the Alibaba group and Ali Health have been simplified here.

74. "China Pharmacies Urge Abolition of Alibaba Health Drug Tracking Platform," Reuters, 24 February 2016, http://mobile.reuters.com/article/idUSKCNOVXOUX; Reuters, "China Suspends Ali Healthrun Online Drug Monitoring Platform," Fortune, 21 February 2016, http://fortune.com/ 2016/02/21/cfda-ali-health-drug-monitoring; Baber Saeed, "Chinese Pharmacy Chains Demand Revocation of Alibaba Group Medicine Tracking Platform," China Business News, 24 February 2016, www.chinabusinessnews.com/2390-chinese-pharmacy-chains-demand-revocation-of-alibabasmedicine-tracking-pla; Laurie Burkitt, "Alibaba Health Swallows Bitter Pill, as China Halts Drugmonitoring System," The Wall Street Journal, 22 February 2016, www.wsj.com/articles/ ali-health-swallows-bitter-pill-as-china-halts-drug-monitoring-system-1456144563 (URLs accessed on 31 October 2016).

75. "Ali Health to Launch New Third-party Drug Tracking Platform," Marbridge Daily, 10 May 2016. 
ciencies of the Chinese healthcare system. It needs to be integrated into a strong-willed set of policies, including a redefined patient journey and clear monitoring of private actors carrying out missions of public service. This is obviously still a work in progress.

I Translated by David Buchanan.

I Carine Milcent, CNRS-Researcher at Paris-Jourdan Sciences

Économiques (PSE), has been on assignment at CEFC since 1

September 2014 (cmilcent@gmail.com).

Manuscript received on 30 May 2016. Accepted on 6 October 2016. 